\title{
ENTRE O VIVIDO E O INESPERADO: A AÇÃO DOCENTE COM BEBÊS*
}

\author{
Elaine Vieira de Souza (SEMED/ROO)
}

\section{Introdução}

A Educação infantil começa com os bebês e as crianças, mas, afinal, quem são os bebês? Esse trabalho apresenta brevemente como se deu o início de minha inserção na atuação docente com bebês, minhas dificuldades e êxitos, assim como a construção e desenvolvimento constante de minha profissionalidade na perene tensão entre teoria e prática. São diversos autores capazes de contribuir com esse tema, mas, para iniciarmos, utilizo primeiramente a contribuição advinda de Barbosa (2010) que em seu texto da consulta pública nos diz que:

\begin{abstract}
Durante muitos anos os bebês foram descritos e definidos principalmente por suas fragilidades, suas incapacidades e sua imaturidade. Porém, nos últimos tempos, as pesquisas vêm demonstrando as inúmeras capacidades dos bebês. Temos cada vez um maior conhecimento acerca da complexidade da sua herança genética, dos seus reflexos, das suas competências sensoriais e, para além das suas capacidades orgânicas, aprendemos que os bebês também são pessoas potentes no campo das relações sociais e da cognição. Os bebês possuem um corpo onde afeto, intelecto e motricidade estão profundamente conectados e é a forma particular como estes elementos se articulam que vão definindo as singularidades de cada indivíduo ao longo de sua história. Cada bebê possui um ritmo pessoal, uma forma de ser e de se comunicar. (BARBOSA, 2010, p.02).
\end{abstract}

Diante de tais constatações, de fato devemos ter mais atenção e cuidados para deixar os bebês serem quem eles são, e por se tratar de um período tão especial da vida, tal como afirma Paulo Focchi (2015, p.01), um "bebê tem que ter tempo para ser bebê. Não existe forma de recuperar esse tempo tão precioso, específico daqueles que vivem a pedagogia dos inícios, da primeira vez". Por isso, falar sobre os bebês é um chamamento 
para um mergulho na profundeza do escondido, do maravilhamento, do que é o começo da vida humana.

A história dos bebês começa a ser contada desde muito cedo, no planejamento de seus pais, por meio da genética familiar, pela gestação, dentre tantas outras condições. Para se compreender quem são esses pequenos sujeitos e como eles se desenvolvem é necessária uma busca teorizada, muita observação, escuta e olhar sensível ao estar com eles, entre eles e apropriar-se dos mais diversos relatos e resultados de pesquisas, que nas últimas décadas têm ocorrido com mais intensidade. Há vários estudiosos que veem apresentando resultados de longos anos de pesquisas sobre o começo da vida de um bebê, ou seja, da vida humana, como por exemplo, Andrew Meltzoff, pesquisador e PhD da Universidade de Washington que aponta para o fato de que "os seres humanos aprendem mais e mais - da gestação aos três anos de idade do que em todo o resto de suas vidas". Ele considera ainda que "o bebê é uma poderosa máquina de aprendizagem que usa sua mente como um grande cientista" (MELTZOFF, 2016, p.01).

À luz da teoria histórico-cultural, os pesquisadores Silva et al. (2018, p.31) afirmam que:

[...] o bebê, ao nascer, apresenta funções psíquicas elementares e, a cada momento, podem se desenvolver quando requisitadas nas relações estabelecidas. Neste sentido, a atenção vai se desenvolver quando houver algo ou alguém que chame e mantenha em exercício a atenção do bebê. Por esta razão, não se pode afirmar que o bebê é apenas sensorial, pois seria uma leitura empobrecida de suas qualidades psíquicas, uma vez que já existem possibilidades de desenvolvimento de todas estas funções.

Vale ressaltar, ainda, que inúmeros estudos nas últimas décadas vêm apontando caminhos para uma nova visão sobre o comportamento e desenvolvimento dos bebês. Estudos como esses evidenciam que eles são muito ativos, agentes de seu desenvolvimento por meio de suas capacidades sensoriais, perceptivas e psicomotoras.

\section{Caminhos Percorridos}

A vivência pelos caminhos do inesperado foi gerando em mim experiências que me constituíram e continuam me constituindo ao longo de minha trajetória. Trago na memória os primeiros encontros com os pequenos 
sujeitos/bebês ainda quando estagiária, podendo afirmar que desde então passei a perceber que os bebês são sujeitos em potências, passei também a me dedicar e a observar como esses pequenos sujeitos desenvolvem suas habilidades, competências e ainda como suas professoras se colocavam frente àquele agrupamento de bebês, por meio de estímulos brincantes, musicais e de diferentes brincadeiras de estímulos sensoriais.

De estagiária passei a ser professora, já com a formação acadêmica do curso de Pedagogia. Participei do processo seletivo em que fui vivenciando a prática no cotidiano e no contexto das unidades de Educação Infantil, por meio das formações centradas na escola, formação da secretaria de educação e também por meio da minha autoformação. Desse modo, podese afirmar que "a formação deve estimular uma perspectiva crítico-reflexiva, que forneça aos professores os meios de um pensamento autônomo e que facilite as dinâmicas de autoformação participada" (NÓVOA, 1997a, p.25). A cada etapa sinto a necessidade da busca constante, por entender que ser docente é um esforço pessoal, um trabalho livre e que deve ser criativo, cujo objetivo em si é a construção de uma identidade, que é também uma identidade profissional, originada na vocação e no desempenho do próprio saber da experiência.

Diante das possibilidades, tornei-me professora do processo seletivo que me inspirou o desejo pela efetividade, por meio do concurso. Foi por essa inspiração que passei a me dedicar na formação para conhecer um pouco mais sobre as políticas públicas educacionais para a Educação Infantil e também me debrucei sobre o conhecimento relacionado às bases teóricas, as quais iluminam a minha prática docente. Essa busca sempre me levava a novas inquietações quanto ao caráter profissionalizante da ação docente.

\section{Passei no concurso: agora efetiva}

Em dois mil e dezesseis tomei posse no concurso público para Educação Infantil, passei a me sentir mais atuante nesse palco e meu comprometimento aumentou, pois o que antes não tinha uma continuidade por conta das constantes quebras de contratos, com a efetivação passou a me permitir viver a realidade do "chão da escola" com maior intensidade.

Minha lotação foi na sala dos pequenos bebês, comigo havia duas estagiárias do curso da Pedagogia, as quais estavam ali para me auxiliar tanto nos cuidados em relação à alimentação, higienização e no sono, elementos essenciais para o desenvolvimento dos bebês, quanto para atender aos 
aspectos do educar, no sentido de aliar cuidados e educação numa relação de ética.

A respeito da condição indissociável entre o cuidar e o educar, Sônia Kramer (2005) diz que o cuidado tem como foco o outro, e o adulto deve ser receptivo e sensível, percebendo e suprindo as necessidades da criança, tais atitudes exigem proximidade, tempo e entrega. $\mathrm{E}$ conforme o Referencial Curricular Nacional para a Educação Infantil: "A base do cuidado humano é compreender como ajudar o outro a se desenvolver como ser humano. Cuidar significa valorizar e ajudar a desenvolver capacidades" (BRASIL, 1998, v.01, p.24).

Já o ato de educar é amplo, envolve experiências e situações significativas de aprendizagens que colaboram com o desenvolvimento das capacidades e conquistas da autonomia e independência dos pequenos sujeitos. Desse modo, a legislação nos apresenta que educar e cuidar são ações indissociáveis e complementares no cotidiano da educação infantil.

Ainda sobre as estagiárias que me acompanhavam todos os dias, elas estavam ali não só para me auxiliar, mas para, além disso, atuarem como aprendizes de professor e buscavam para si uma identidade, uma referência e suas formações acadêmica e profissional, na verdade tratava-se de uma soma de saberes e experiências entre nós.

Nessa relação, enquanto professora, eu precisava buscar retroalimentar sempre os meus conhecimentos, fazendo ponte com os aportes teóricos, bem como com as diferentes maneiras de trabalhar as ações com os bebês. $E$ como minha caminhada ainda estava se iniciando, também sentia a necessidade de uma referência, de uma professora mentora com experiência em quem eu pudesse me inspirar e ir ressignificando meus saberes na ação docente, sendo necessário aprender para ensinar e ensinar para aprender.

\section{Meus primeiros momentos no berçário... tecendo minhas vivências e experiências}

Bem se sabe que os primeiros momentos dos bebês numa instituição de Educação Infantil são de muita estranheza e choro. E comigo essa fase da transição (entre casa e instituição) dos bebês não foi diferente. Os bebês choram, sim, nos seus primeiros dias dentro das instituições, mesmo que se trate de um momento temporário de afastamento da família, eles sentem-se deixados em um lugar no qual não tinham nenhum vínculo com 
as pessoas, com o ambiente e com a vivência coletiva junto a outros bebês. Para a família também é muito doloroso deixar o seu maior tesouro com pessoas que mal conhecem, é uma situação muito difícil. Acolher a família e tranquilizá-los sempre foi o primeiro passo a ser dado, tentar desde os primeiros dias saber as especificidades do bebê é de suma importância. Por isso organizei meu caderno de campo com todos os dados pesquisados na ficha de matrícula de cada bebê, feita anteriormente durante a semana pedagógica, e também preparei um outro caderno onde ia anotando todas as especificidades nutricionais de cada bebê, além de outras considerações necessárias, como possíveis alergias ou restrições alimentares. Em parceria com a equipe das merendeiras sempre havia um diálogo sobre as mamadeiras dos pequenos, as quais eram utilizadas de maneira individual, a partir das anotações no caderno, para que cada bebê recebesse seu preparo em sua mamadeira, conforme prescrição médica ou orientação da nutricionista. Também os copos dos bebês, chupetas e qualquer outro objeto, no momento da alimentação, eram usados de maneira individual e sempre esterilizados. Durante esse período, sendo responsável por essa turma com bebês, fomos capazes de garantir a eles esse zelo individual relacionado à alimentação, preconizado em muitos manuais e referenciais. Os familiares colaboram a partir de diálogos, levando para o uso individual do seu bebê a mamadeira e o copo.

A segunda organização a ser preparada foi a identificação dos bebês, seus nomes em todos os seus pertences, para evitar trocas; as identificações eram feitas com material colante.

\section{Entre o choro e o acolhimento}

Quanto ao choro, nos primeiros dias é algo inevitável, e é preciso tentar acolher a todos, pegando no colo sim, sem receio de que o bebê possa ficar mal acostumado. Ele está sofrendo e precisa de apoio, por isso pegar no colo e dar aconchego é fundamental. E como fazer para acolher no colo tantos bebês? Era uma turma com vinte e quatro bebês de seis meses a um ano e onze meses. E para esse momento de separação momentânea ser menos doloroso organizei, desde os primeiros dias, momentos de acoIhimento musical, utilizando recurso visual a partir de imagens e músicas cantadas como forma de acolhê-los e acalmá-los. Sentávamos ao chão entre tatames e almofadas e os bebês se sentiam acolhidos por mim e as estagiarias, uns vinham e deitavam sobre nossas pernas, outros se debruçavam sobre nossos ombros e outros queriam colo mesmo, e eram atendidos, to- 
dos sentiam em aconchego. Esses momentos eram feitos diariamente de modo que os bebês iam adquirindo sua autonomia e se tornando mais confiantes e seguros. Dar colo é assim, é dar um pouquinho de nós, numa relação de puro afeto, carinho e acolhimento.

A música é um recurso importante no trabalho com as crianças, e especialmente com os bebês podemos obter resultados riquíssimos. Muitas vezes, quando eles choravam e eu começava a cantar, isso fazia com que eles se acalmassem, era como se eu pegasse todos no colo ao mesmo tempo. Devo dar aqui relevância à informação de que não sou cantora e nem tenho formação musical, apenas entendo e acredito que para atender crianças tão pequenas, o profissional deve gostar de cantar. Na maioria das vezes esse recurso musical resulta positivamente, mas também ocorreu alguns poucos momentos que eles não se acalmavam. Então, era necessário usar de outras estratégias pedagógicas para acalmá-los. E quando isso acontecia eu usava objetos ou o meu próprio corpo em movimento, gesticulando, dramatizando e cantando.

Brincadeiras diárias eram prioridades nos meus planejamentos, desde os primeiros momentos na instituição sempre levava os bebês para o banho de sol. É importantíssimo para o desenvolvimento físico da criança receber o sol em seu corpo no horário adequado, pois isso ativa a vitamina $\mathrm{D}$ em seu organismo. Pensando assim, brincadeiras no solário na parte externa da sala eram momentos rotineiros desde os primeiros dias na instituição. Tenho como concepção que devemos oportunizar aos bebês momentos de explorar outros espaços dentro do ambiente institucional, tudo de maneira organizada e seguindo um cronograma de planejamento. Além de levá-los para brincadeiras no solário anexo à sala, sempre organizava momentos de passeios intercalados com momentos desafiadores, o que resultava em momentos maravilhosos de descobertas pelas crianças ao explorar os espaços e objetos, às vezes, alguns deles começavam a dar seus primeiros passos.

\section{Um grande desafio}

Deixar um bebê chorando e dizer que ele está manhoso e que só quer colo nunca foi tido como algo aceitável por mim durante todo o tempo em que estive com essa turma. $O$ choro é um sinal de alerta e uma linguagem diversa que precisa ser compreendida por quem está responsável por uma criança. 
Nos primeiros momentos, o bebê chora porque tem insegurança, ele não compreende que é medo o motivo de seu próprio choro, e eu não o deixava chorando sem que fosse atendido. Era nesses momentos que a parceria de trabalho com as estagiárias funcionava muito bem, pois o atendimento que elas ofereciam aos pequenos era de suma significância. Respeito mútuo, diálogos e a participação delas nas tomadas de decisões referente ao bem-estar coletivo dos bebês foi algo muito positivo que tive desde o início. Repassei para elas como seriam constituídos os planejamentos e nossas rotinas, sempre tendo em mente o seguinte pensamento: "Respeito se conquista respeitando primeiro". Elas sabiam que as decisões referentes à turma seriam tomadas por mim, no entanto, as opiniões delas eram levadas em consideração e, muitas vezes, vinha a contribuir com o planejado. Tive ótimas parceiras que de fato contribuíram muito com o sucesso desse trabalho desenvolvido. Cada uma com as suas limitações e especificidades, afinal, todos nós temos limitações, mas com vontade de dar o melhor de si a cada dia, naquilo que se dispunha a fazer, e priorizando sempre o trabalho coletivo para tudo dar certo.

Tive muitas inquietações ao longo do ano letivo, especialmente sobre as situações que envolviam mordidas entre as crianças. Sabemos que os bebês estão na fase oral, e no processo da dentição. Foi necessária uma observação atenta para esses momentos, em que sempre buscava fazer com que o bebê fosse atendido em suas necessidades, às vezes ele morde por estar nervoso, por não ter o que quer, para explorar outras sensações, entre tantas. Mas é muito importante estarmos atentas para evitar esses desconfortos das mordidas e o mal-estar que gera na família ao ver o seu bebê mordido. Por isso, um bom plano de trabalho é muito importante, com riqueza de recursos, estratégias brincantes, lúdicas e um ambiente acolhedor e de possibilidades explorativas por todos. Lembrando que devemos ter um cuidado especial quanto aos tamanhos dos objetos e brinquedos de modo a evitar acidentes ou transtornos.

Para superar minhas inquietações busquei ainda mais qualificação profissional na área em que estava atuando, continuei buscando recursos de pesquisas, leituras nas questões referentes às condições de estímulos significativos para bebês e a troca de experiências com outros profissionais atuantes na área, descobri um leque de possibilidades que pode proporcionar bem-estar aos bebês, visando o desenvolvimento de conhecimento de mundo para os pequenos. 


\section{Por fim...}

A inspiração de escrever esse relato de experiência nasceu a partir da leitura do livro de Judit Falk (2011) cujo título é "Educar os três primeiros anos: a experiência de lóczy". Relatar as ações vividas entrelaçadas ao inesperado na ação docente com bebês foi um momento oportuno para revisitar a minha prática e olhar para o caminho percorrido. Espero que as contribuições desse relato possam servir para a formação profissional de vários docentes, estagiárias, entre outros profissionais, de modo que possamos dar visibilidade social aos contextos das políticas públicas voltadas a esse sujeito em potencial categorizado como "bebê".

\section{Referências}

BARBOSA, M. C. As especificidades da ação pedagógica com os bebês. In: I Seminário nacional: currículo em movimento - perspectivas atuais, 2010, Belo Horizonte. Anais eletrônicos.... Belo Horizonte: nov, 2010. Disponível em: http://portal.mec.gov.br/docman/dezembro-2010-pdf/7154-2-2-artigo-mec-acao-pedagogica-bebes-m-carmem/file. Acesso em: 15 dez. 2020.

BRASIL. Ministério da Educação e do Desporto. Secretaria de Educação Fundamental. Referencial curricular nacional para a educação infantil / Ministério da Educação e do Desporto, Secretaria de Educação Fundamental. Brasília: MEC/SEF, 1998. 3v.: il.

FALK, Judit (Og.). Educar os três primeiros anos: a experiência de Lóczy. 2.ed. Araraquara-SP: Junqueira \& Marin, 2011.

FOCHI, P. Palavra de... professor da Educação Infantil: entrevista ao blog tempo de creche. In: Tempo de creche. Disponível em: https://tempodecreche.com.br/postura-do-pofessor-e-rotina/palavra-de-professor-de-professor-da-educacao-infantil-paulo-fochi/. Acesso em: 15 dez. 2020.

KRAMER, S. Profissionais de Educação Infantil: gestão e formação. São Paulo: Ática. 2005.

MELTZOFF, A. Os bebês são detetives emocionais. In: Revista Época. Maio de 2016. Disponível em: https://epoca.globo.com/vida/noticia/2016/05/an- 
drew-meltzoff-os-bebes-sao-detetives-emocionais.html. Acesso em: 15 dez. 2020.

NÓVOA, A. Diz-me como ensinas, dir-te-ei quem és e vice-versa. In: FAZENDA, I. (Org.) A pesquisa em educação e as transformações do conhecimento. São Paulo: Papiros, 1997a.

SILVA, J. R. et al. (org.). Educação de bebês: cuidar e educar para o desenvolvimento humano. São Carlos: Pedro \& João Editores, 2018. 